\title{
App Development on Operation and Maintenance Management of Seismic Network Based on the Mobile Terminal
}

\author{
Bo Bi, Peiyu Zhu and Peng Wang \\ Seismic Management Center of Shanghai, Earthquake Administration of Shanghai Municipality, China
}

\begin{abstract}
In order to ensure the normal operation of equipment in the seismic network, the key job is rapid and effective fault response and exclusion. App development on operation and maintenance management of seismic network based on the mobile terminal is an effective method, which includes IOS system and Android. The professional software is developed and applied to seismic network of Earthquake Administration of Shanghai Municipality in this paper. The management system can realize a variety of functions, such as real-time push important information and removal of fault including station state and network state.
\end{abstract}

Keywords- mobile terminal; seismic network; APP; intelligent monitor and control

\section{INTRODUCTION}

Seismic station is the basic unit of the seismic observation system [1-3]. Moreover, it is the most important core part among seismic monitoring system. With the rapid development of science and network technology, Seismic station has been gradually realized the specific patterns which are unattended operation, 24 hours guard and centralized maintenance. According to demand of actual work and research, to reduce the influence of various kinds of interferes, seismic stations are located in the place where few people tread [4]. With precision advancement of the monitoring instrument and related auxiliary equipment, the environment requirement is higher and higher. Environmental temperature, humidity, power supply voltage, etc. are all normal monitoring range besides monitoring instrument and related auxiliary equipment. When the equipment failure occurs, especially some minor faults, if Instrument maintenance personnel can't timely and accurate judge the causes of failure, it is necessary for them to be sent to station. However, it needs a lot of time which must cause to interrupt monitoring data and influence operation quality of the whole seismic network.

How to maintain and manage these unattended stations has become an urgent problem to be solved. Therefore, it is quite necessary and urgent to construct intelligent station. Intelligent station, just as its name implies is to make the intelligent and automatic maintenance and management to the station [5-7]. Through the installation of monitoring equipment, maintenance personnel can remotely monitor information and the operating state of the instrument, and then solve the problem using remote operation and processing [8]. The research of this paper is to develop a smart station monitoring APP based on the mobile terminal and to achieve complete intelligent station maintenance.

\section{SySTEM DESIGN AND DEVELOPMENT}

The central foundation of intelligent station is central data processing system based on the intranet server. The key of research and development is to transplant the corresponding system to the mobile terminal. The system achieves the seamless connection between the intranet and extranet through mapping network communication port and port Web page in the intranet server. Using the system, multi-information of seismic station in monitoring network can be remotely monitored, such as state of power supply, environment and equipment; Station state data can be transmitted and receipt. And it also can realize information transmission, two-way control (which includes station power supply, data collector, and some seismometers) and network state interpretation, fault interpretation and real-time information push through APP. Besides this, parameter setting, remote reboot, zero adjustment, and real - time waveform display and operating rate statistics are also major function. Figure 1 shows system network structure.

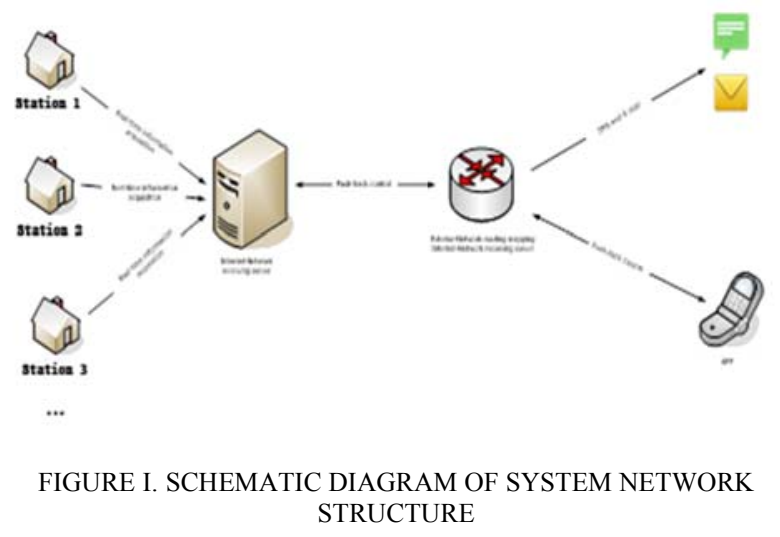

Intelligent station is composed of three major systems, namely, the intelligent station monitoring system, central data processing system of the monitoring management platform and mobile terminal APP. The functions of each part are as follows:

\section{A. Intelligent Station Monitoring System}

The part mostly deploy a variety of sensors and monitoring equipment in unattended operation station, such as data collector, power controller, network HD camera and station environmental monitoring unit, and so on.

\section{B. Central Data Processing System}

The major functional parts of the system is real-time acquisition to monitoring data of the station, if it happens 
abnormity, it supplies trigger judgment, then release through alarm. The system uses the $\mathrm{C} / \mathrm{S}$ mode, the tool uses Visual Studio2008 and development language is $\mathrm{C} / \mathrm{C}++$. The main functional structure of the system is shown in the Figure 2.

\section{Among them,}

\section{Station State Monitoring:}

It means real-time or quasi real time receiving station's status and display the result with graphic list. Monitoring programs include environmental parameters of station, data collector and pendulum, etc...

\section{Station Equipment Control:}

Remote control and set up the basic parameters of the station equipment, such as the number of mining parameters set, the number of recovery, monitoring unit restart, zero, calibration, etc...

\section{Station Video Surveillance:}

It is real-time video remote surveillance.

\section{Station Observation Data:}

It includes query to the continuous observation data, operating rate statistics, etc.

\section{System Parameter Settings:}

It is setting common function parameter of system.

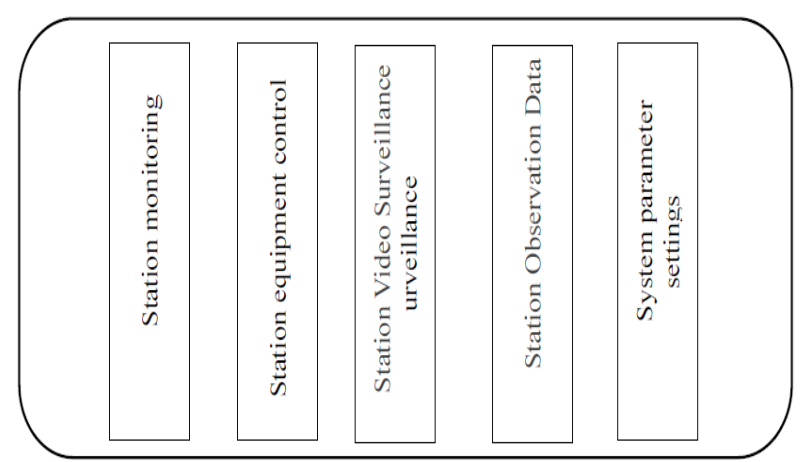

FIGURE II. MANAGEMENT PLATFORM OF MONITORING SYSTEM

\section{Mobile Terminal APP}

At present, the mainstream mobile terminal is divided into Android system and IOS system. Corresponding APP is designed and developed based on different systems. Android APP development language uses Java, development tools are eclipse3.6+ in the platform of JDK and Android SDK. Its APP is applied to Android 3.0+.APP of IOS system which applies IOS 7+ uses Object-C, and development tool uses X-Code 6.3+, IOS SDK is its development platform. Other auxiliary development contains Tortoise SVN, Bug Free, RDMS and Cruise Control.

\section{App DeVelopment Design}

APP development and design is important means for realizing intelligent station. At present, the research focuses on the development of computer software. The application software of mobile terminal urgently needs to design and develop. In our research, the first APP is developed based on Shanghai Earthquake Network which can realize inverse control. Each module is described like the following.

\section{A. Monitored Control Module}

Mobile client display the details of each station monitoring list in the main interface which includes three states: normal, abnormal and disconnected. The APP can monitor the status of the list of stations by clicking buttons of the monitoring, power supply, the earthquake, and the strong earthquake. Entering into this module is by clicking on each station monitoring list, and switching interface can click on the button on the top of the screen. The buttons on the bottom refer to related operation to station equipment, such as reboot, calibration and zero, etc. The concrete interface is shown in Figure 3 and Figure 4.
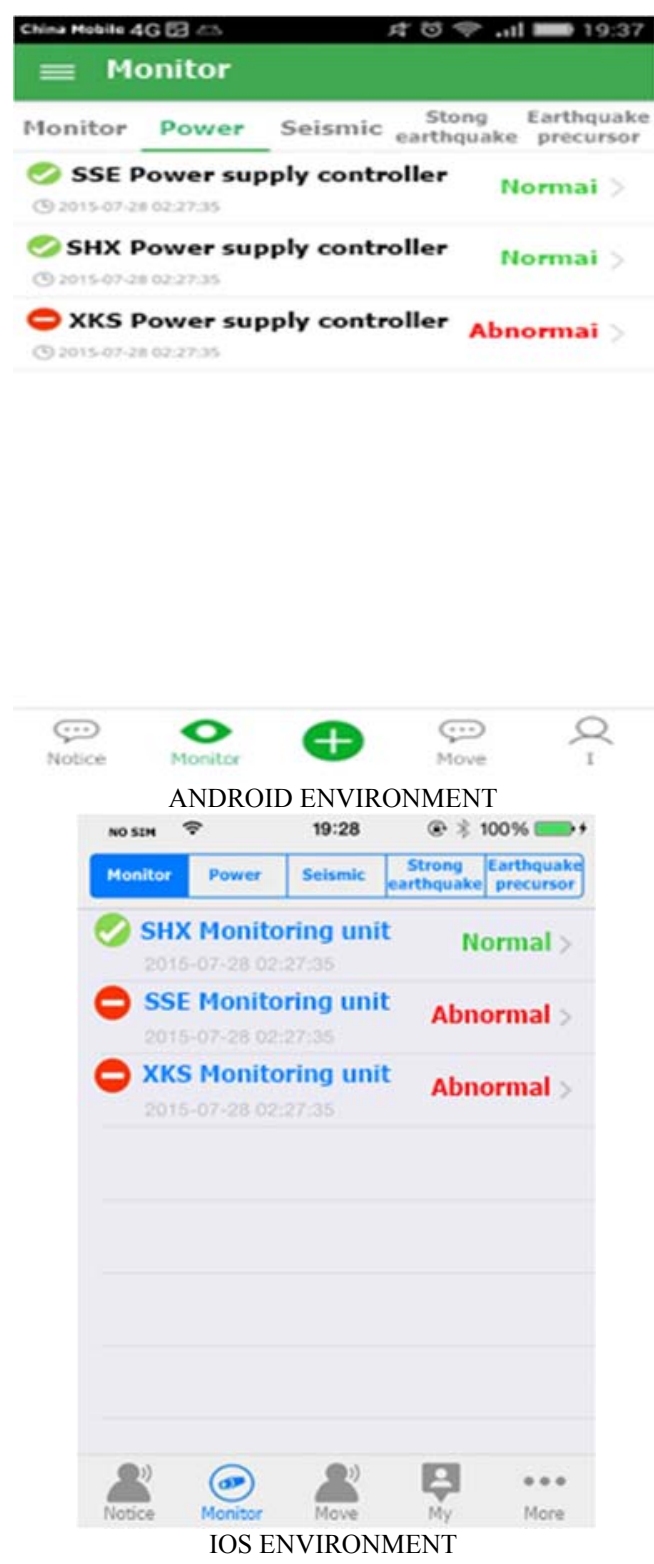

FIGURE III. MONITORED CONTROL MODULE 


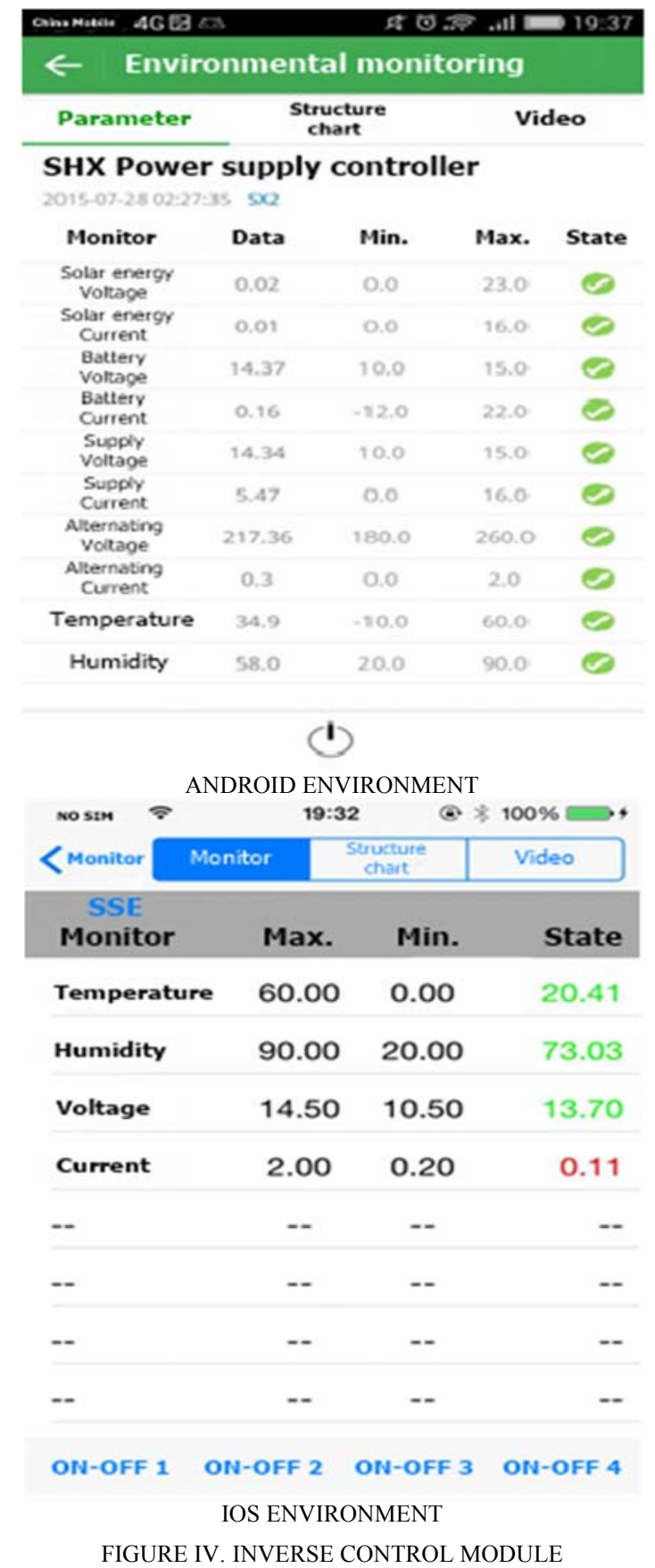

\section{B. Fault Notice Module}

The functional module is a notification push of the mobile terminal. It can display updates on station equipment exception or fault, and the approximate time of each notification push, as shown in Figure 5.

\section{Video Surveillance Module}

The chief responsibility in the module is monitoring environment to every seismic station, as shown in Figure 6.

\section{Real Time Waveform Display Module}

This module can realize the real-time waveform of the corresponding station, as shown in Figure 7.

\section{Practical Applications AND Discussions}

According to the actual situation of the Shanghai earthquake monitoring center, we select Sheshan seismological station, Kunshan seismological station, and Xiao Yangshan seismological station to pilot run. The three seismological stations adopt TDE-324CI data collector. Among them, Sheshan seismological station has a century old, belongs to the national standard of the people on duty, and uses band seismometer CTS-1EF. Kunshan seismological station is unattended and uses band seismometer CMG-3ESPC where surrounding environment is poor. Only raining, it is difficult to get close enough. Xiao Yangshan is unattended island station and uses band seismometer CMG-ESPC. It is difficult to enter only by boat. No one can land in the event of severe weather.

Through monitoring the three seismological stations, the APP can successfully operate. When fault happens, maintainer receives notice in the short message form or APP push. Maintainer takes action by two ways control. If signal recovery is normal, the APP also shows real time waveform and statistical result of operation ratio. From the research on the pilot, the fault interpretation of management platform is basically accurate and recovery of equipment normal operation is rapid.

From what has been discussed above, the construction of intelligent station has greatly improved the operation stability and continuity of the seismic station. APP application based on mobile terminal is taking into account the network operating quality when the maintenance personnel are limited or off duty. It shortens the maintenance time and save the maintenance cost. The APP has the promotion of high value, and it's positively significant to realize the development of the intelligent network construction.

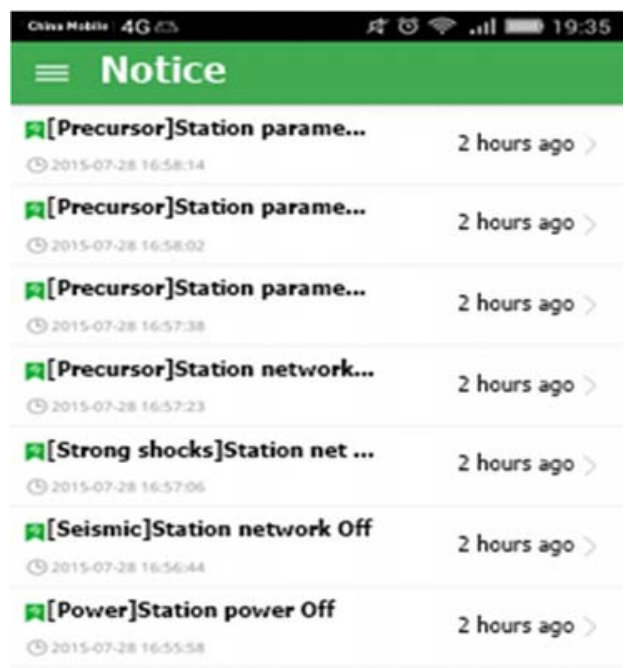



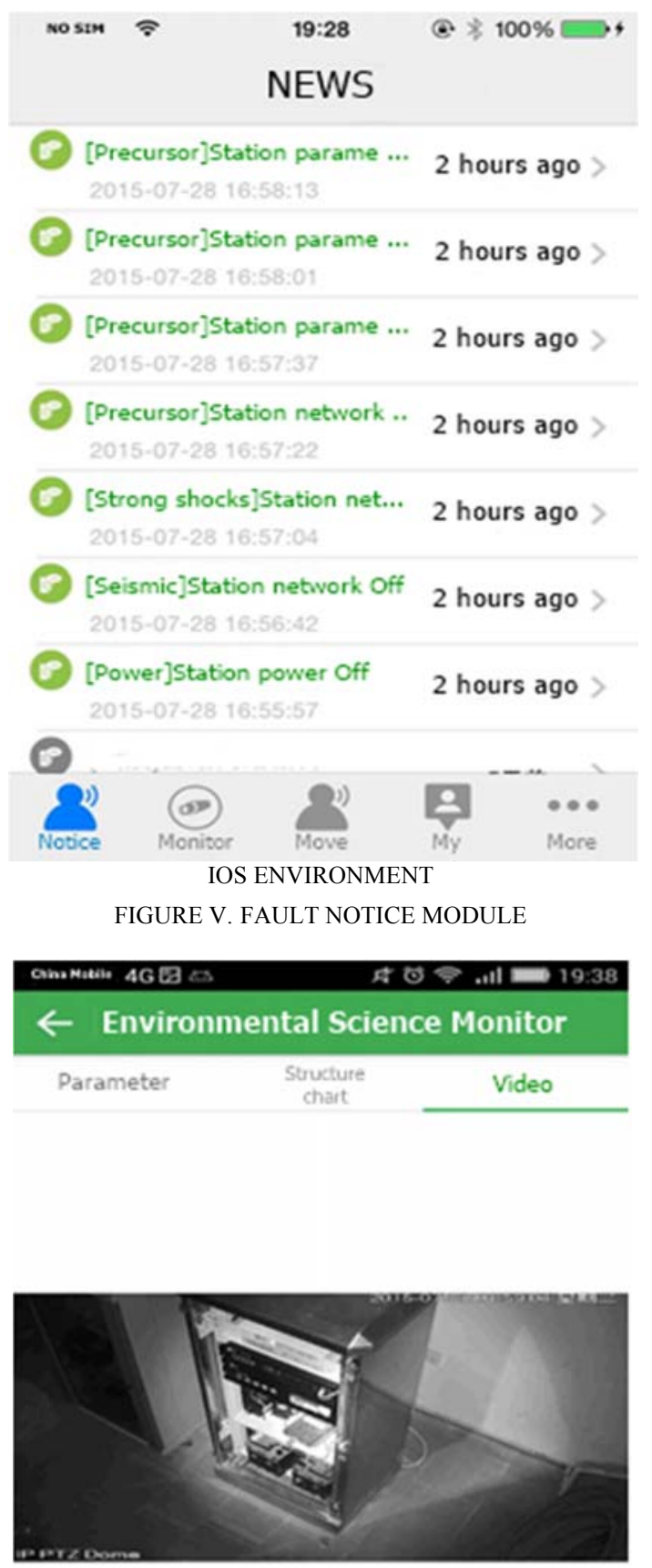

(I)

ANDROID ENVIRONMENT

\begin{tabular}{|c|c|c|c|}
\hline \multirow{2}{*}{ rosim } & \multicolumn{2}{|c|}{ 19:29 } & ๔. $\$ 100 \% \square$, \\
\hline & Monitor & $\begin{array}{c}\text { Structure } \\
\text { chart }\end{array}$ & viseo \\
\hline SHX & Jide & & \\
\hline
\end{tabular}

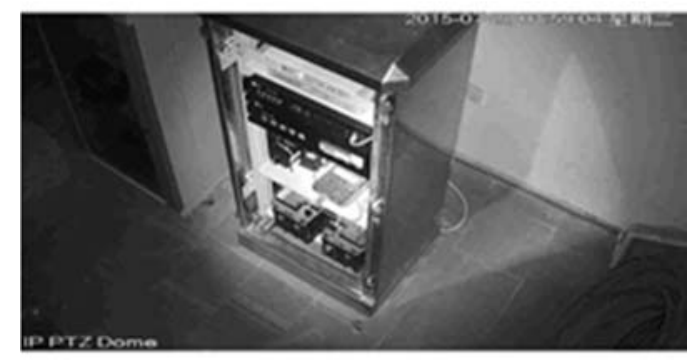

ON-OFF 1 ON-OFF 2 ON-OFF 3 ON-OFF 4 IOS ENVIRONMENT

FIGURE VI. REAL-TIME VIDEO SURVEILLANCE MODULE

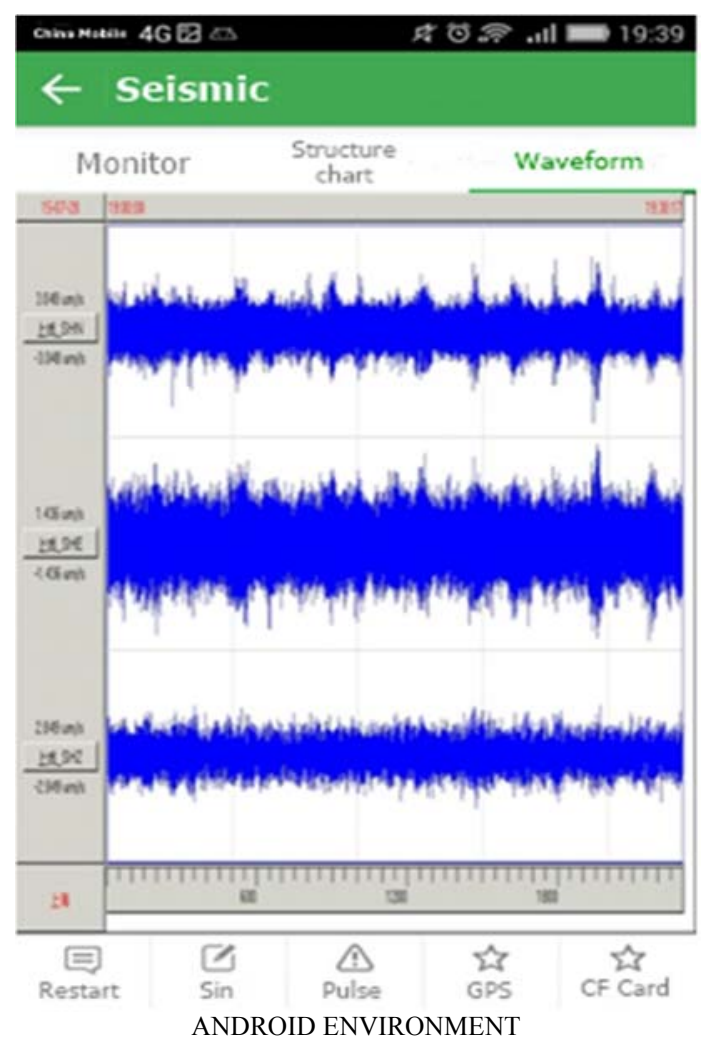



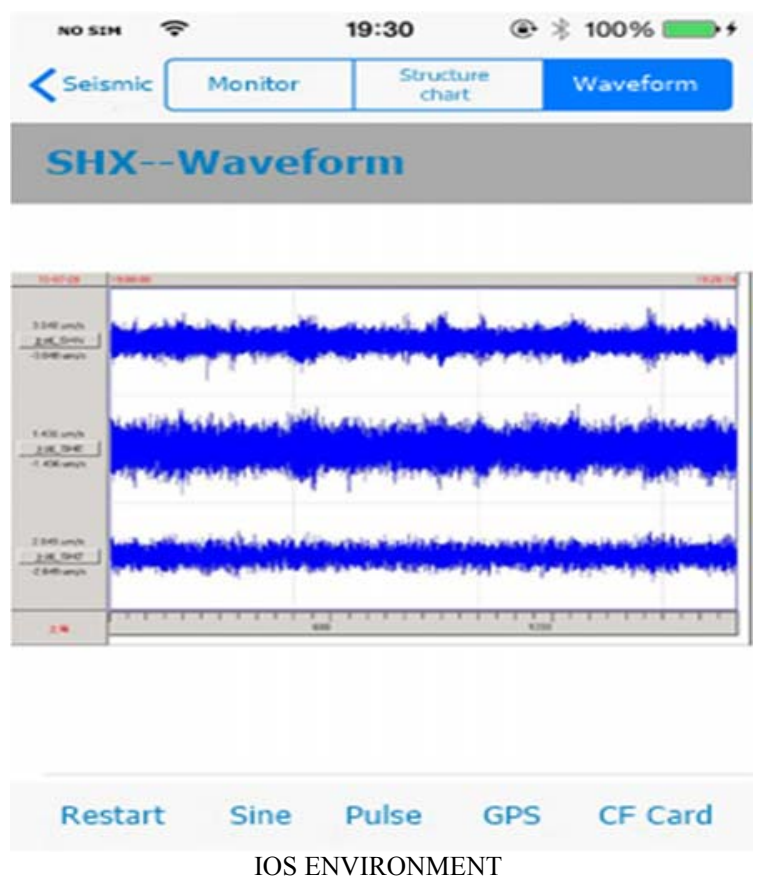

FIGURE VII. REAL-TIME WAVEFORM DISPLAY MODULE

\section{ACKNOWLEDGMENT}

I would like to take this opportunity to thank all those who helped me during the writing the thesis. Especially, I would like to acknowledge getting fund support of Special Training of Young People in the Network Station from the Department of Earthquake Monitoring and Prediction of China Earthquake Administration (project number 20150409).

\section{REFERENCES}

[1] WANG Xiao-feng, CHANG Zheng, ZHANG Huan. Design on the management server of seismic station [J]. SEISMOLOGICAL RESEARCH OF NORTHEAST CHINA,2007,23(1): pp. 74-77

[2] HE Shou-qing, WANG Ting. The design and application of environment monitoring system in seismic station [J]. SOUTH CHINA JOURNAL OF SEISMOLOGY, 2013, 33(3): pp. 47-54

[3] MA Li, WANG Jiu-yang, LI Jun, JING Tao. The application of seismic station in the daily work of the computer [J]. JOURNAL OF DISASTER PREVENTION AND REDUCTION, 2014, 30(1): pp. 64-68

[4] CHENG Shu-qi, WANG Shuai-he, WANG Xi-bao. Operation and maintenance of digtal observation system in seismic station [J]. JOURNAL OF DISASTER PREVENTION AND REDUCTION, 2011, 27(4): pp. 44-47

[5] NI Tai-shan,QUE Yun-cai,LI Xiang,LI. Design and Implement of B/S Structure-based Synthetic Seismic Station Information Management System [J]. JOURNAL OF DISASTER PREVENTION AND REDUCTION,2009,32(1): pp. 89-93

[6] HUANG xian-liang,QI Hao,CHENG Xin. A poilot study on the intelligent seismic stations [J].Recent Development in World Seismology, 2013, 10: pp. 11-15

[7] DONG Hong-jun, ZHANG Jian-xin, SUN Jing-yan. Development of the software for the Management system of seismostation information in Tianjin [J].NORTH CHINA EARTHQUAKE SCIENCES, 2004, 22(1): pp. 55-59

[8] CHEN Ji-feng, CHEN Jun-hui, YING Chang. Design and Implementation of Remote Monitoring System for Unattended Seismic Stations [J].JOURNAL OF SEISMOLOGICAL RESEARCH, 2012, 35(3): pp. 429-433 